\title{
Effect of Thermal Environment on the Mechanical Behaviors of Building Marble
}

\author{
Haijian Su (D), Hongwen Jing, Qian Yin (D), and Liyuan Yu (D) \\ State Key Laboratory for Geomechanics and Deep Underground Engineering, China University of Mining and Technology, \\ Xuzhou, Jiangsu 221116, China \\ Correspondence should be addressed to Haijian Su; hjsu@cumt.edu.cn
}

Received 8 December 2017; Accepted 31 January 2018; Published 6 May 2018

Academic Editor: Rihong Cao

Copyright (c) 2018 Haijian Su et al. This is an open access article distributed under the Creative Commons Attribution License, which permits unrestricted use, distribution, and reproduction in any medium, provided the original work is properly cited.

High temperature and thermal environment can influence the mechanical properties of building materials worked in the civil engineering, for example, concrete, building rock, and steel. This paper examines standard cylindrical building marble specimens $(\Phi 50 \times 100 \mathrm{~mm})$ that were treated with high temperatures in two different thermal environments: vacuum (VE) and airiness (AE). Uniaxial compression tests were also carried out on those specimens after heat treatment to study the effect that the thermal environment has on mechanical behaviors. With an increase in temperature, the mechanical behavior of marble in this study indicates a critical temperature of $600^{\circ} \mathrm{C}$. Both the peak stress and elasticity modulus were larger for the VE than they were for the AE. The thermal environment has an obvious influence on the mechanical properties, especially at temperatures of $450 \sim 750^{\circ} \mathrm{C}$. The failure mode of marble specimens under uniaxial compression is mainly affected by the thermal environment at $600^{\circ} \mathrm{C}$.

\section{Introduction}

In the civil engineering, the high-temperature disaster becomes more and more frequent, such as building and tunnel fire. Thermal damage can lead to changes in the physical and mechanical behaviors and to variations in the mineral composition and microstructure of building materials $[1,2]$. The problem of thermal damage has also been observed in other projects, such as underground coal gasification, geothermal resource mining, and the deep storage of high-level nuclear wastes [3-5]. How the physical and mechanical behaviors of building materials are affected by high temperatures has become a hot topic.

Rock (e.g., sandstone, marble, and granite), as the significant building material, is widely used in the civil engineering $[6,7]$. In the past few years, numerous, significant, experimental studies were conducted to quantify the effect of thermal damage on rock. Semicircular bending (CSTSCB) specimens of certain Indian rocks, including Manoharpur sandstone, Bellary dolerite, and Dholpur sandstone, were subjected to the three-point bending test by Mahanta et al. [8], who studied the effects of thermal treatment on mode I fracture toughness. The influence of temperature and rock type on the stress-strain curve, peak strength, and elastic modulus was investigated by Zhang et al. [9], who conducted MTS 815 uniaxial compression tests on marble, limestone, and sandstone specimens at high temperatures (ranging from room temperature to $800^{\circ} \mathrm{C}$ ). Yin et al. [10] conducted an experimental comparison of the mechanical properties of granite after high-temperature treatment and under a high temperature. Their results show that, for granite under a high temperature, the peak stress is lower, the peak strain is greater, and the elastic modulus is smaller compared with that observed after high-temperature treatment. The change laws for the fracture toughness and tensile strength of rock samples that had experienced rapid thermal cooling under different temperatures and cyclic thermal cooling treatments, respectively, were obtained by Kim et al. [11]. Gonzalez-Gomez et al. [12] investigated the change features of the physical properties (including sample color, mass loss, chemical composition, and porosity) of four limestones that were extracted from the Yucatan Peninsula (Mexico) and subjected to different high temperatures. The triaxial compressive behaviors of coarse marble specimens after 


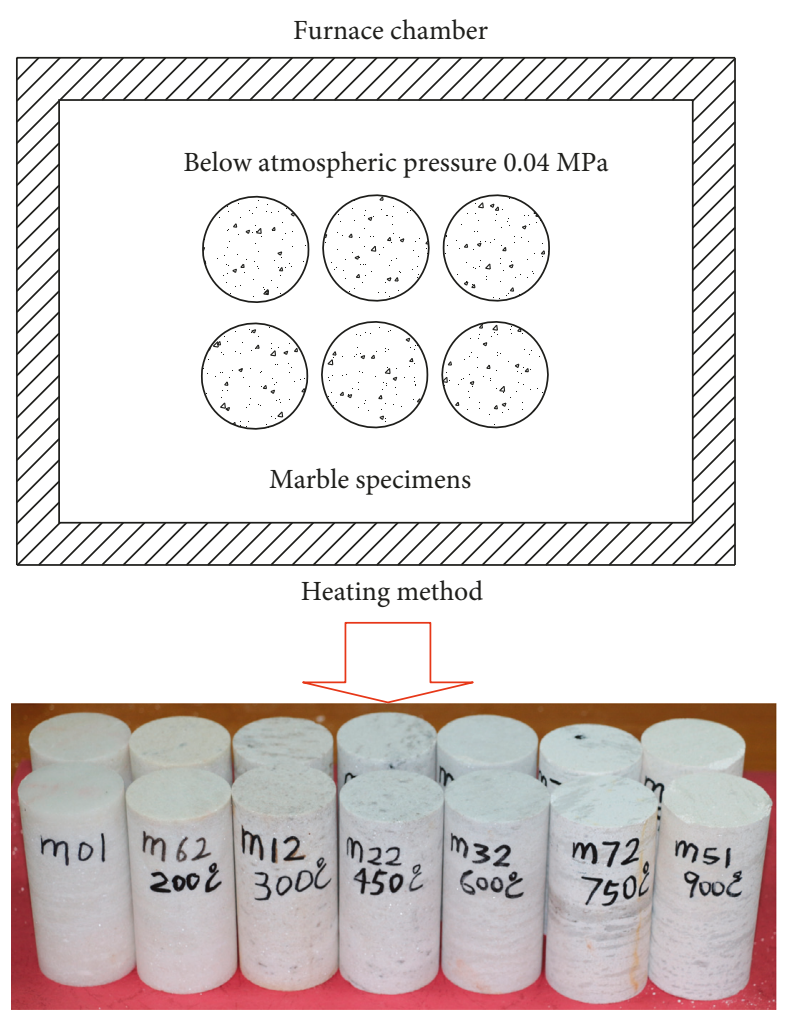

(a)

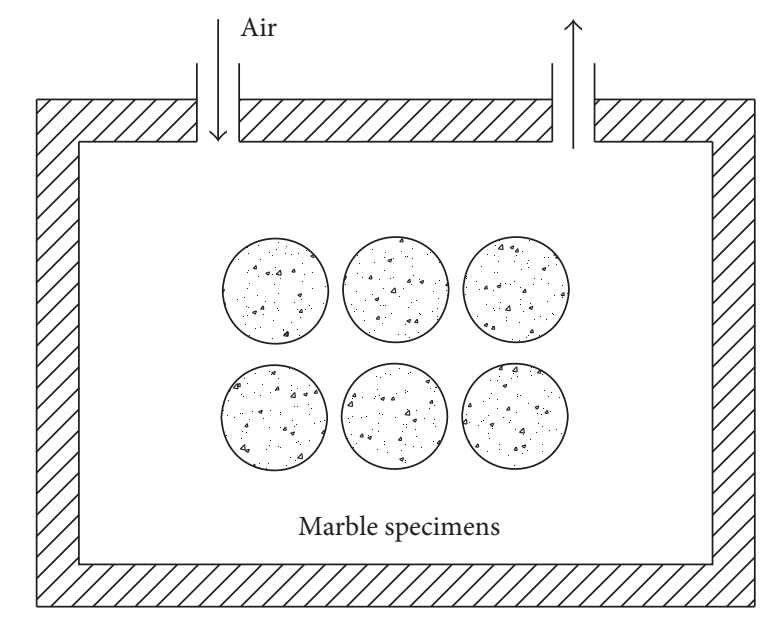

Heating method

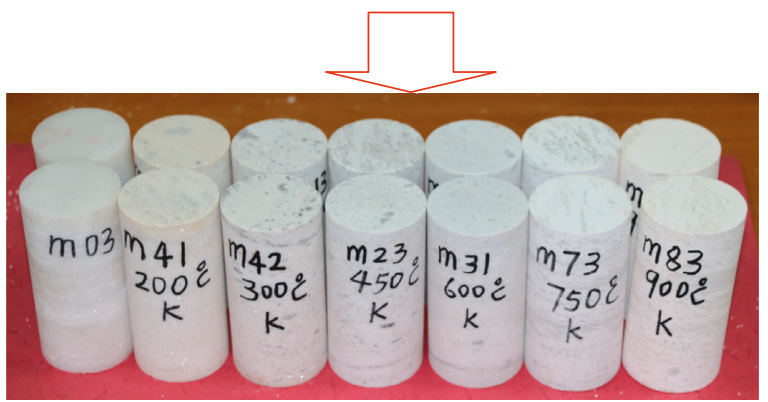

(b)

FIgURE 1: Heating method and the prepared marble specimens after heat treatment. (a) Vacuum environment. (b) Airiness environment.

high-temperature treatment (ranging from 20 to $600^{\circ} \mathrm{C}$ ) under different confining pressures (ranging from 0 to $40 \mathrm{MPa}$ ) were studied by Yao et al. [13], who proposed an empirical model of the negative exponential type that described the peak strength well. Liu et al. [14] obtained the change laws of fracture toughness, splitting tensile strength, and elastic modulus for rocks after high-temperature treatment, based on a splitting tensile test conducted on flattened Brazilian disc specimens.

In the civil engineering, the mechanical behaviors of building rock are also affected by the thermal environment in the process of fire disaster [15-17]. Existing studies involving the heat treatment of rock indicate that the effect on the thermal environment is limited. In this study, heat treatments were applied to building marble specimens within two different thermal environments: vacuum and airiness. After the heat treatment, uniaxial compression tests were conducted to determine the effect that the thermal environment has on the physical and mechanical properties of the specimens.

\section{Experimental Work}

The building marble material used in this study is from a quarry in the southeast region of Linyi City, Shandong Province of China. In its natural state, the marble is white in color and does not have a macroscopic texture. The average density of this marble is $2.83 \mathrm{~g} / \mathrm{cm}^{3}$, with the main mineral compositions of calcite, dolomite, and quartz. In accordance with the ISRM and the laboratory's strict processing requirements, standard cylindrical specimens with a diameter of $50 \mathrm{~mm}$ and a height of $100 \mathrm{~mm}$ were prepared for this experimental project. The maximum deviation in the specimen height was $\pm 0.3 \mathrm{~mm}$, and the maximum nonparallelism between ends was $\pm 0.05 \mathrm{~mm}$.

Heat treatment of the marble specimens was accomplished using an MXQ1700 box-type furnace produced by Shanghai Micro-X Furnace Co. Ltd. of China. In the heat treatment for the VE (Figure 1), air was eliminated from the furnace chamber using an air pump until the pressure in the chamber was below an atmospheric pressure of $0.04 \mathrm{MPa}$ (an approximate vacuum environment, namely, VE). Next, the marble specimens were heated to a designated temperature at a rate of $5^{\circ} \mathrm{C}$ per minute, which was maintained for 2 hours. Finally, the marble specimens in this environment were passively cooled to room temperature. When the heat treatment for the airiness environment (namely, AE) was implemented, both the inlet and outlet valves of the furnace chamber were turned on to allow air to enter the chamber freely and slowly. The processes for the heating and cooling treatments were same as those implemented for the VE. In this study, there were six designated heating temperatures T: $200,300,450,600,750$, and $900^{\circ} \mathrm{C}$.

After the heat treatment, the marble specimens were subjected to a uniaxial compression test using an MTS815.2 rock mechanics servocontrolled testing system. Displacement 


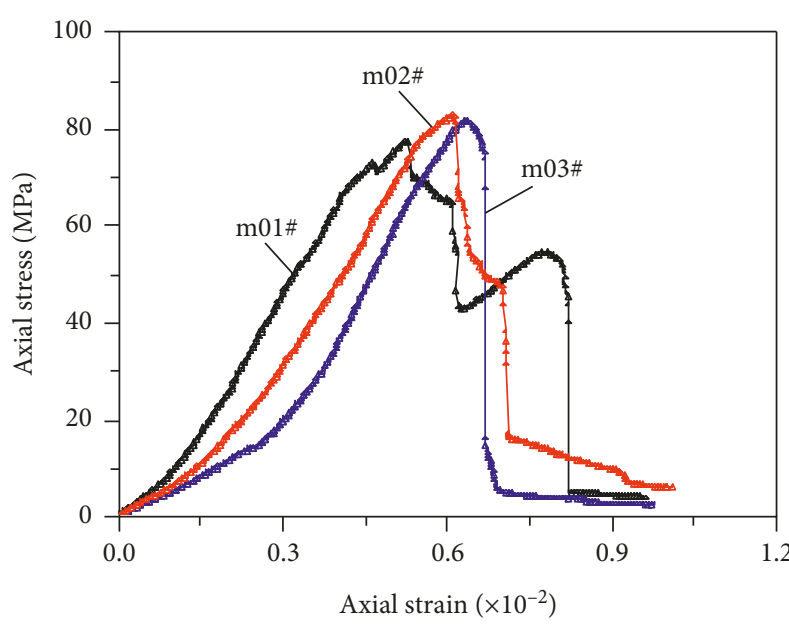

(a)

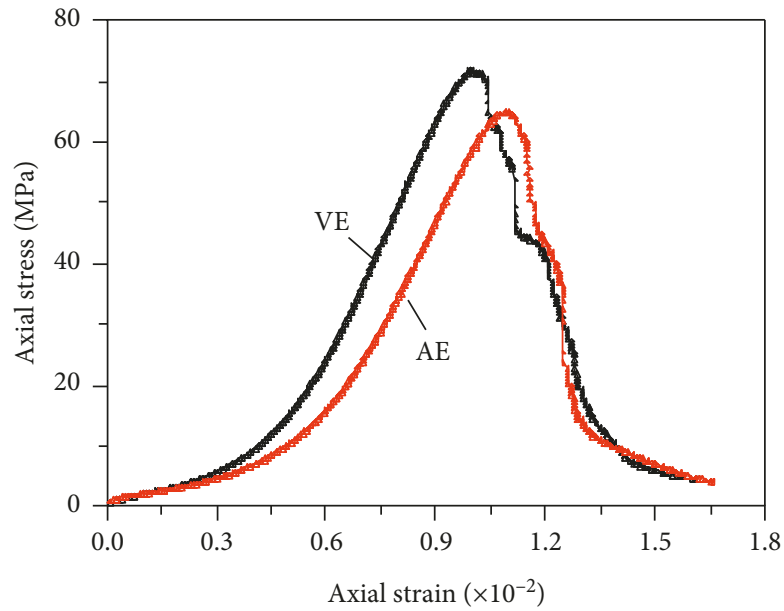

(c)

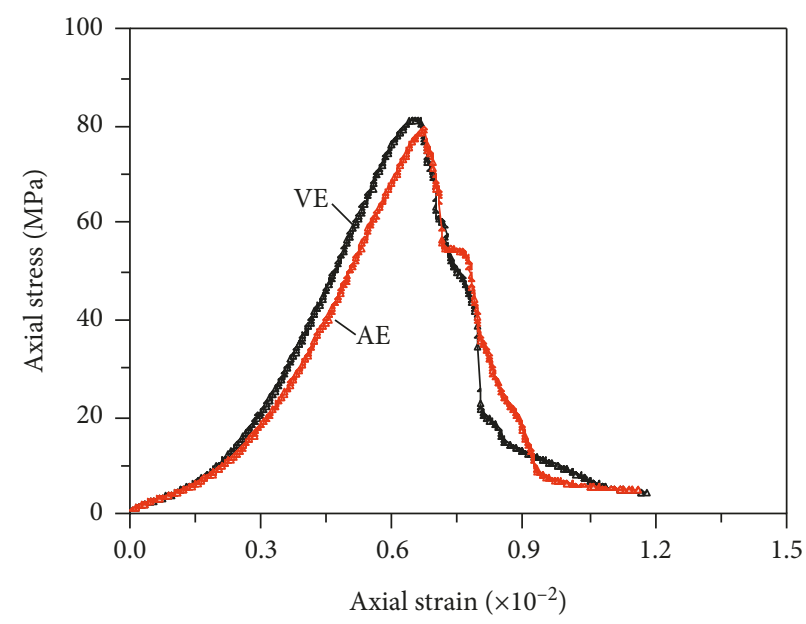

(b)

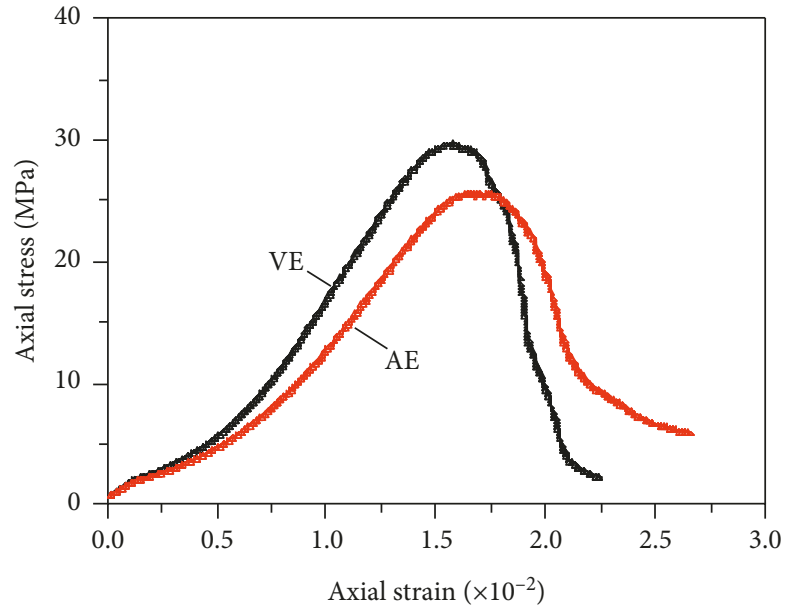

(d)

Figure 2: Axial stress-strain curves of marble specimens under uniaxial compression: (a) 25, (b) 300, (c) 600, and (d) $900^{\circ} \mathrm{C}$.

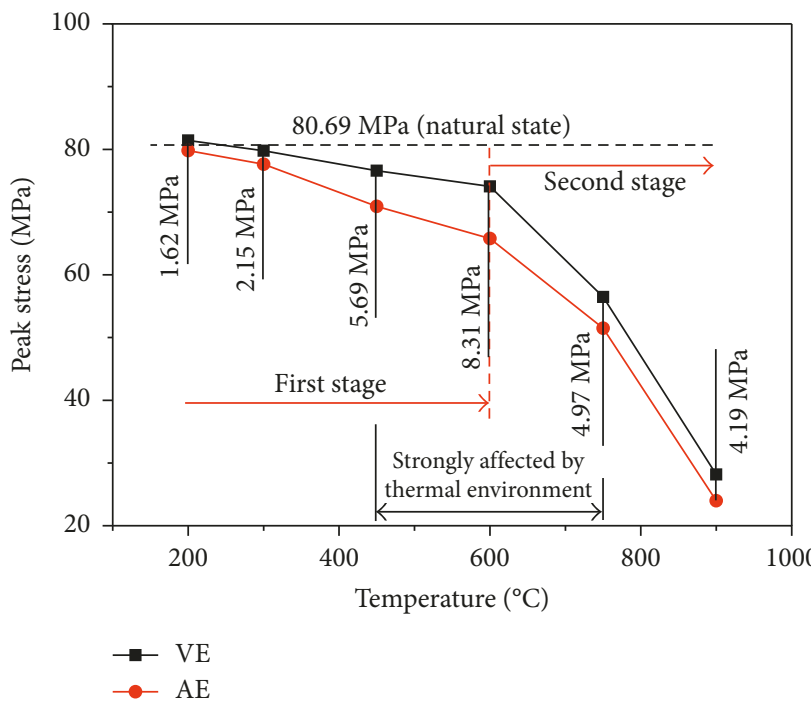

(a)

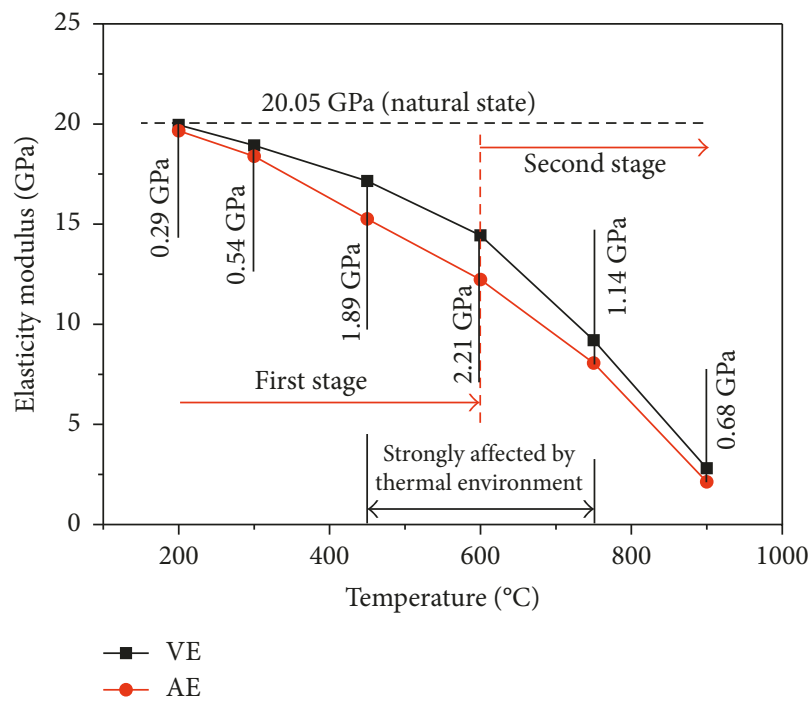

(b)

FIgURE 3: Effect of temperature on the mechanical parameters of marble specimens: (a) peak stress and (b) elasticity modulus. 


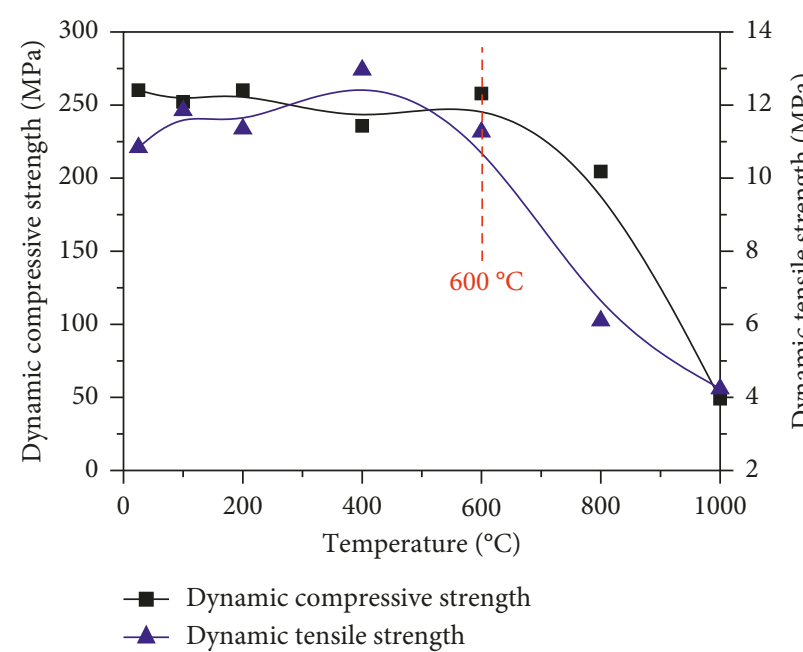

(a)

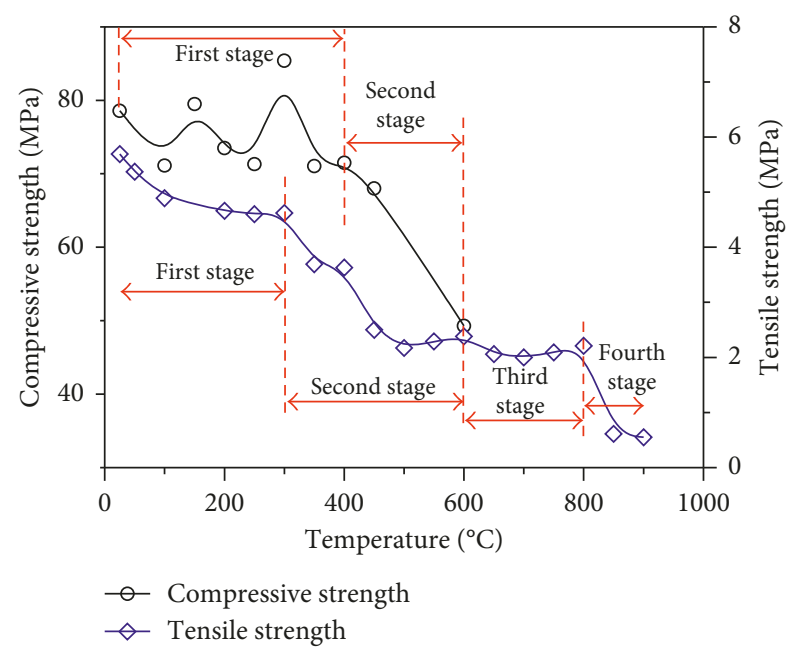

(c)

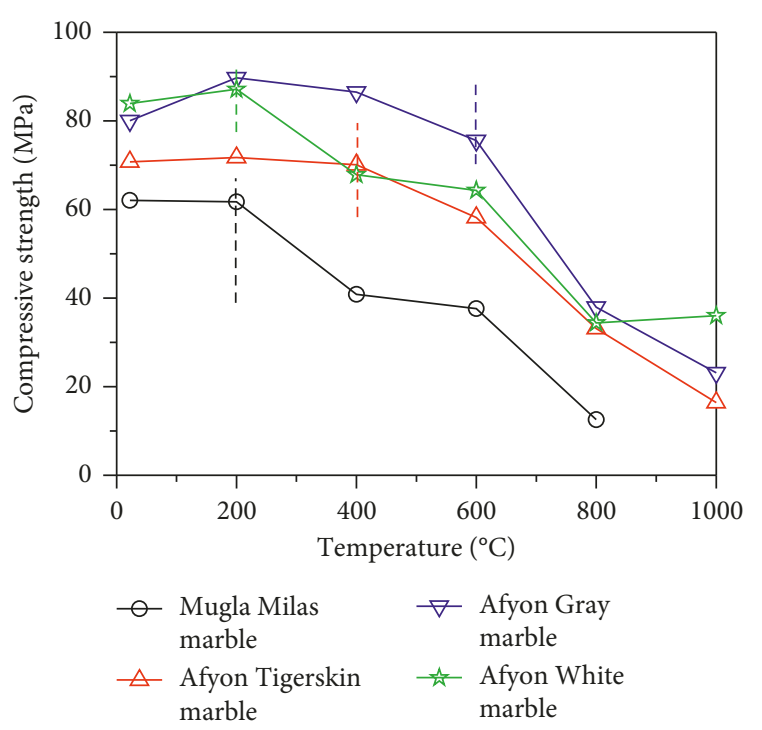

(b)

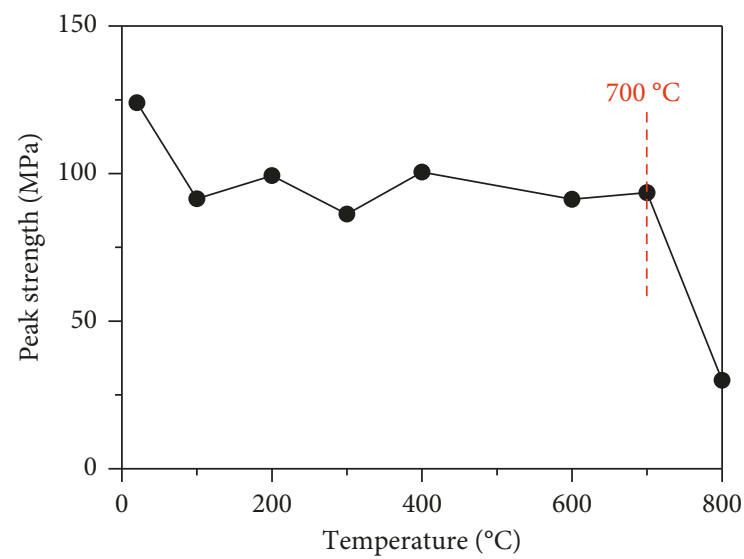

(d)

FIGURE 4: Variations of mechanical parameters of rocks with temperature: (a) dynamic compressive strength and dynamic tensile strength of marble [18], (b) compressive strength of marble [19], (c) compressive strength and tensile strength of Linyi sandstone [20, 21], and (d) peak strength of limestone [9].

loading at a loading rate of $3.0 \times 10^{-3} \mathrm{~mm}$ per second was used in the test. Vaseline was evenly smeared on both ends of the specimens to eliminate the effects of end friction on the testing result. The marble specimens in their natural state $\left(25^{\circ} \mathrm{C}\right)$ that had not undergone the heat treatment were also tested.

\section{Result Analysis}

3.1. Mechanical Parameters. Figure 2 provides the axial stress-strain curves of marble specimens under uniaxial compression. Figure 3 shows the effect of temperature on the peak stress and elasticity modulus. In the natural state, the average values of peak stress and elasticity modulus are 80.69 $\mathrm{MPa}$ and $20.05 \mathrm{GPa}$, with the dispersion coefficients (namely, the ratio of standard deviation to average value) of 0.03 and 0.13 , respectively. With an increase in temperature, the peak stress and elasticity modulus decrease gradually, and this process can be divided into two stages from $600^{\circ} \mathrm{C}$.

3.1.1. First Stage. At $200-600^{\circ} \mathrm{C}$, both the peak stress and elasticity modulus present a slowly decreasing trend with a small extent. As the temperature rises from 200 to $600^{\circ} \mathrm{C}$, the peak stress and elasticity modulus decrease from $81.42 \mathrm{MPa}$ and 19.95 GPa to $74.08 \mathrm{MPa}$ and $14.44 \mathrm{GPa}$ for the VE, with the reduction extents of $9.01 \%$ and $27.62 \%$, respectively, and from $79.80 \mathrm{MPa}$ and $19.66 \mathrm{GPa}$ to $65.77 \mathrm{MPa}$ and $12.23 \mathrm{GPa}$ for the $\mathrm{AE}$, with the reduction extents of $17.58 \%$ and $37.79 \%$, respectively. The extent of change of the elasticity modulus is slightly larger than that of the peak stress.

3.1.2. Second Stage. At $600-900^{\circ} \mathrm{C}$, the peak stress and elasticity modulus decrease sharply. As the temperature is 


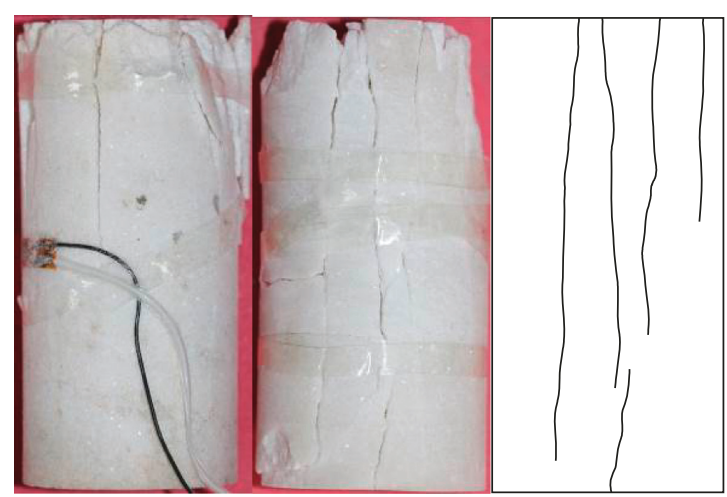

(a)

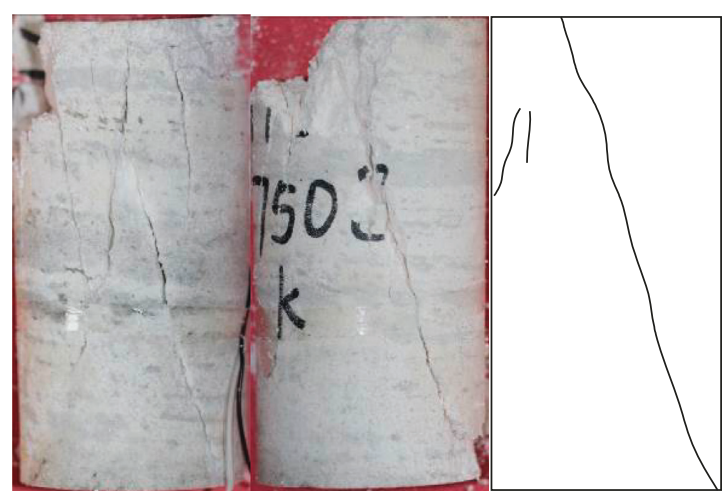

(c)

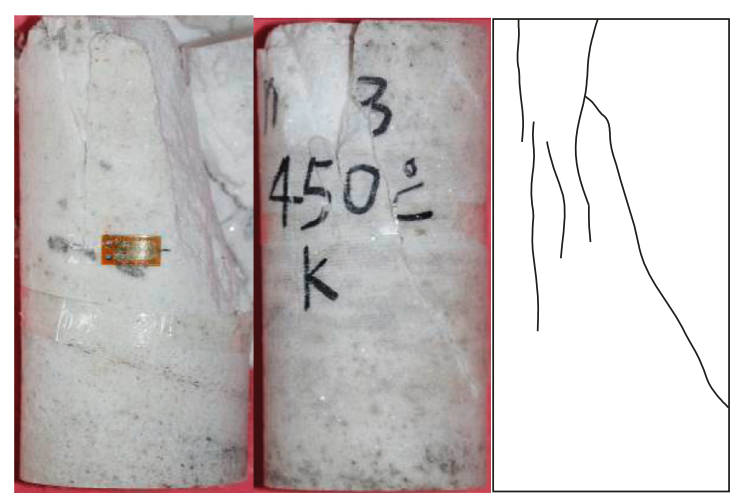

(b)

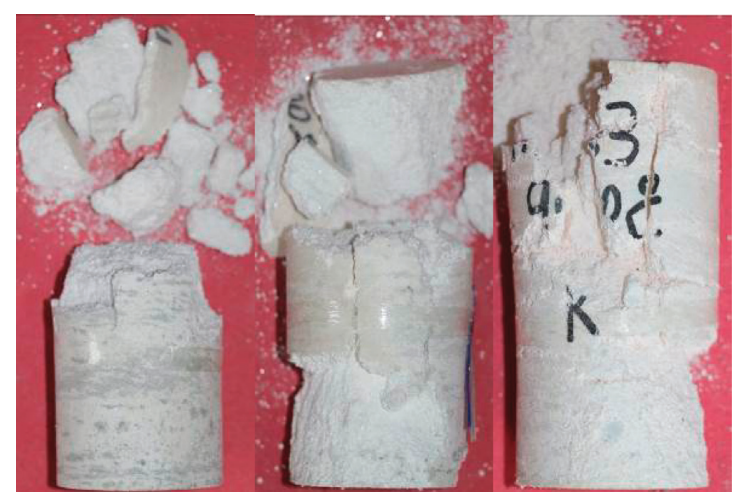

(d)

FIGURE 5: Four failure modes of marble specimens after heat treatment under uniaxial compression: (a) tensile failure, (b) tensile-shear failure, (c) shear failure, and (d) smash failure.

raised from 600 to $900^{\circ} \mathrm{C}$, the reduction extent of peak stress is $61.96 \%$ for the $\mathrm{VE}$ and $63.52 \%$ for the $\mathrm{AE}$, respectively, and that of the elasticity modulus is $80.54 \%$ for the VE and $82.58 \%$ for the AE, respectively.

Figure 3 indicates a critical temperature of $600^{\circ} \mathrm{C}$ for the marble in this study, with obvious differences in mechanical properties at temperatures above or below the critical temperature. Figure 4 presents the variations of mechanical parameters of rocks with temperature in other literatures. $\mathrm{Wu}$ et al. [18] investigated the variations of dynamic compressive strength and dynamic tensile strength of marble specimens, which present the same law found in this study. Ozguven and Ozcelik [19] show the change curves of compressive strength of four types of marble, with different critical temperatures. Zhang and $\mathrm{Lu}[20,21]$ investigated the variations of compressive strength and tensile strength of Linyi sandstone with the temperature. The study of Zhang et al. [9] presents a critical temperature of $700^{\circ} \mathrm{C}$ for the peak strength of limestone. From Figures 3 and 4, it is clear that the change trend and critical temperature of the mechanical parameters of rocks might be influenced by the stress state, lithology, and mineral grain size owing to a complicated geological process.

Figure 3 also shows the differences in the mechanical parameters of two different thermal environments $(\Delta)$. The peak stress and elasticity modulus of the marble specimen, after heat treatment, in the $\mathrm{AE}$ are each less than that for the VE. $\Delta$ of peak stress is between 1.62 and $8.31 \mathrm{MPa}$ and that of
TABLE 1: Effect of temperature and thermal environment on the failure modes of marble specimens.

\begin{tabular}{lcc}
\hline$T\left({ }^{\circ} \mathrm{C}\right)$ & VE & AE \\
\hline 25 & Tensile failure & - \\
200 & Tensile failure & Tensile failure \\
300 & Tensile-shear failure & Tensile-shear failure \\
450 & Tensile-shear failure & Tensile-shear failure \\
600 & Tensile-shear failure & Shear failure \\
750 & Shear failure & Shear failure \\
900 & Smash failure & Smash failure \\
\hline
\end{tabular}

elasticity modulus is between 0.29 and $2.21 \mathrm{GPa}$. Both the peak stress and elasticity modulus reveal a uniform phenomenon: the mechanical parameters of the marble specimens are obviously affected by the thermal environment particularly at temperatures of $450 \sim 750^{\circ} \mathrm{C}$.

3.2. Ultimate Failure Mode. After heat treatment, there are four typical modes of failure in marble specimens under uniaxial compression: tensile, tensile-shear, shear, and smash failure (Figure 5).

(i) Tensile failure: This failure mode is most common in hard or brittle rock. When there is one or more splitting, fracture planes on the specimen run in the same direction as the axial loading. 


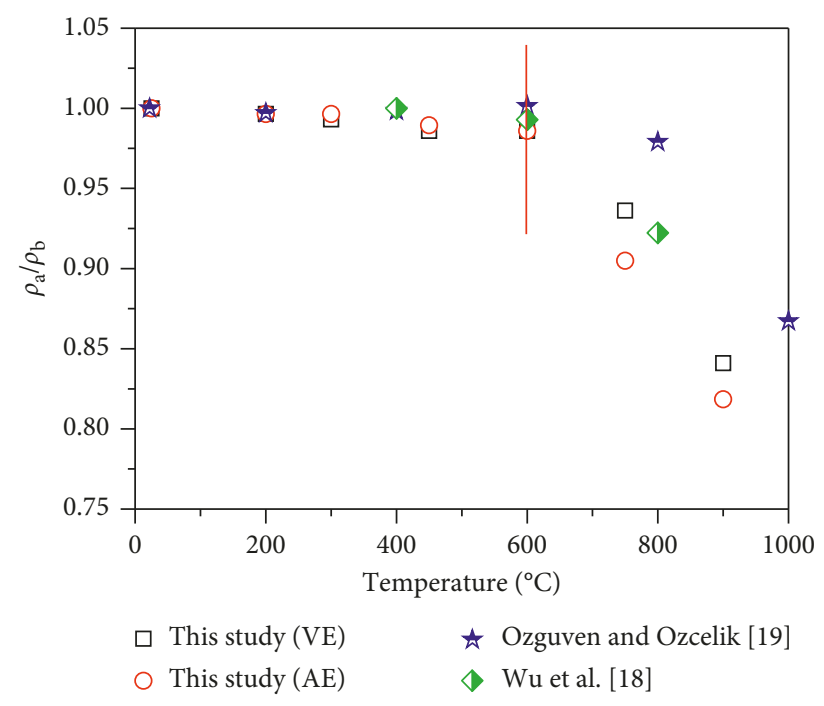

Figure 6: Effect of temperature on $\rho_{\mathrm{a}} / \rho_{\mathrm{b}}$ of marble.

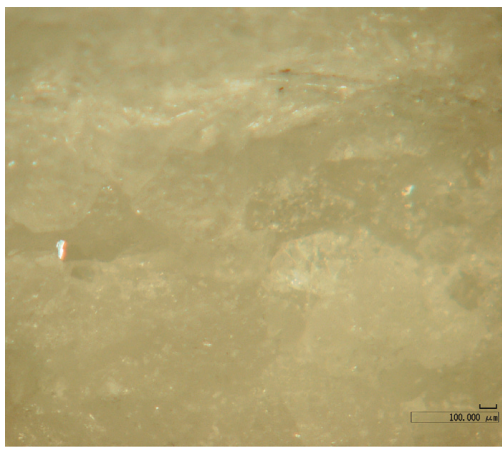

(a)

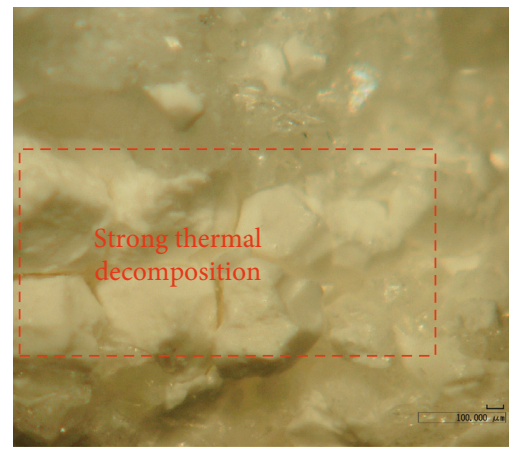

(b)

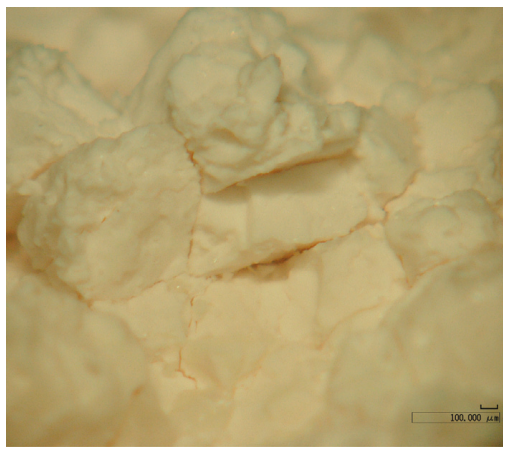

(c)

Figure 7: Microscopic features of marble specimens: (a) $25^{\circ} \mathrm{C}$, (b) $900^{\circ} \mathrm{C}$ (VE), and (c) $900^{\circ} \mathrm{C}$ (AE).

(ii) Tensile-shear failure: It occurs when there are both tensile and shear failure. The tensile and shear fracture planes could intersect or be independent of one another.

(iii) Shear failure: One or more shear planes occur on the specimen, and the shear plane is located at an angle in the direction of axial loading. The shear failure in this paper has some difference from the conventional shear failure, in that a few secondary tensile cracks are also observed. However, rock failure mainly depends on the shear failure.

(iv) Smash failure: After testing, specimen can present smash failure. Many powders are observed from the fractured blocks. The extent of failure in the specimen is extremely serious.

Table 1 shows the effect of temperature and thermal environment on the failure mode of the marble specimens under uniaxial compression. Marble specimens in a natural state $\left(25^{\circ} \mathrm{C}\right)$ undergo tensile failure. With an increase in temperature, the failure mode changes gradually from tensile to tensile-shear, tensile-shear to shear, and then shear to smash failure. At $T=200^{\circ} \mathrm{C}$, all of the specimens after heat treatment in the two thermal environments experienced tensile failure. When the temperature is between 300 and $450^{\circ} \mathrm{C}$, all marble specimens experience tensile-shear failure. However, when $T=600^{\circ} \mathrm{C}$, the thermal environment has an apparent effect upon the failure mode: tensile-shear failure occurs in the VE and shear failure occurs in the AE. When the temperature is 750 and $900^{\circ} \mathrm{C}$, shear failure and smash failure, respectively, occur in both thermal environments.

\section{Discussion}

In this discussion, density and microscopic feature of marble before and after heat treatment are investigated. Figure 6 shows the effect of temperature on $\rho_{\mathrm{a}} / \rho_{\mathrm{b}}$ of marble, where $\rho_{\mathrm{b}}$ and $\rho_{\mathrm{a}}$ are defined as the densities of marble before and after heat treatment, respectively. With an increase in temperature, $\rho_{\mathrm{a}} / \rho_{\mathrm{b}}$ decreases gradually, which also presents a critical temperature of $600^{\circ} \mathrm{C}$, similar to the mechanical parameters.

Figure 6 also presents the difference of density in different thermal environments, particularly at temperatures of $750 \sim 900^{\circ} \mathrm{C}$. This phenomenon can be verified by the microscopic feature, as shown in Figure 7. As $T=900^{\circ} \mathrm{C}$, the 


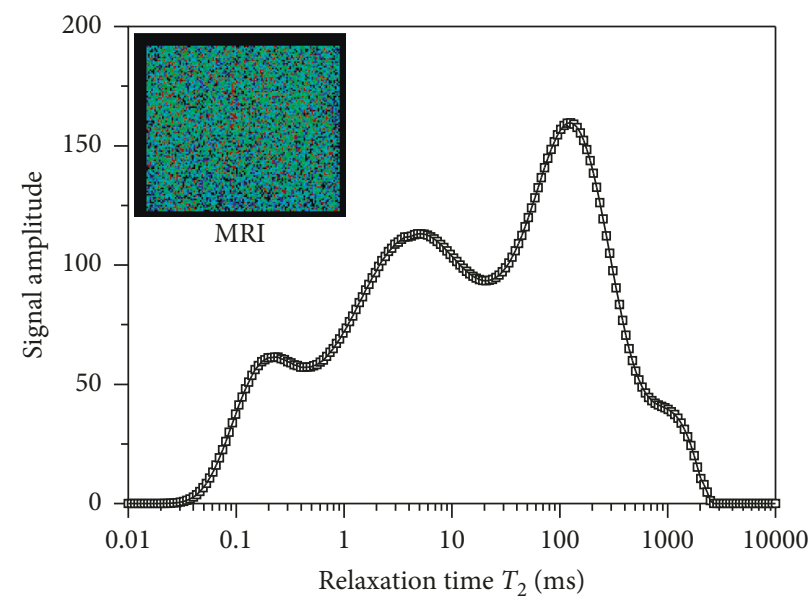

(a)

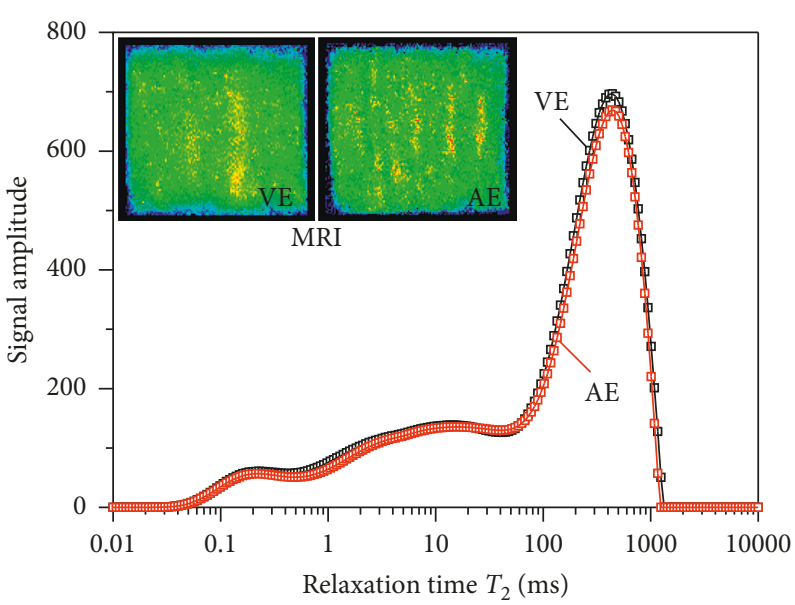

(b)

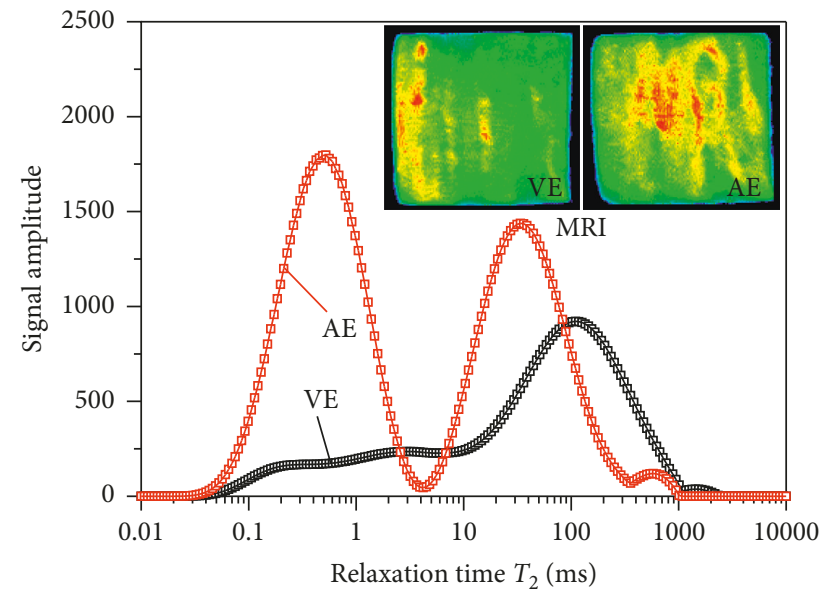

(c)

Figure 8: $T_{2}$ curves and MRI images obtained by NMR: (a) 25, (b) 450, and (c) $750^{\circ} \mathrm{C}$.

primary minerals in the marble present thermal decomposition (such as $\mathrm{CaCO}_{3} \rightarrow \mathrm{CaO}+\mathrm{CO}_{2}$ ). For the $\mathrm{AE}$, gases from mineral thermal decomposition are continually replaced by air. And the extent of the thermal decomposition is more violent. In contrast, for the $\mathrm{VE}$, gases from mineral thermal decomposition are absorbed on the surface of the specimen. This could restrain the thermal decomposition and lead to a reverse reaction. Therefore, mineral thermal decomposition for the AE is more serious than that for the VE.

The nuclear magnetic resonance (NMR) tests were also conducted on the marble specimens (at 25,450 , and $750^{\circ} \mathrm{C}$, resp.). $T_{2}$ curves and magnetic resonance imaging (MRI) are shown in Figure 8 . The $T_{2}$ curve of specimens in the natural state presents a three-peak feature. The peak points are resulted at $T_{2}=0.23,5.17$, and $126.04 \mathrm{~ms}$, with the signal amplitudes of $61.40,113.13$, and 159.64, respectively. The MRI image also shows homogeneity of the marble in this study. The $T_{2}$ curves of marble after $450^{\circ} \mathrm{C}$ heat treatment also present a three-peak feature, while the results of $T_{2}$ curve and MRI image have no significant difference between that for the $\mathrm{VE}$ and $\mathrm{AE}$. At $750^{\circ} \mathrm{C}$, MRI image displays a more serious damage for the AE than for the VE. For the $\mathrm{VE}$, as the temperature increases from 25 to $750^{\circ} \mathrm{C}$, the $T_{2}$ curve trend transforms from a three-peak feature to an approximate single-peak feature with the gradual degradation of the first two peaks. While at $750^{\circ} \mathrm{C}$ for the $\mathrm{AE}$, the $T_{2}$ curve shows an approximate two-peak feature, with the signal amplitudes of 1798.08 and 1437.67 at $T_{2}=0.52$ and 33.70 , respectively.

\section{Conclusion}

In this study, building marble after heat treatment with two different thermal environments was subjected to a uniaxial compression test. Their mechanical properties were measured, and the following conclusions can be drawn:

(1) With an increase in temperature, the mechanical parameters (peak stress and elasticity modulus) of marble specimens decrease gradually in this study, with a critical temperature of $600^{\circ} \mathrm{C}$.

(2) The ultimate failure mode of marble specimens changes from tensile to tensile-shear to shear to smash failure with the increase of temperature. The failure mode presents a different feature between the $\mathrm{AE}$ and $\mathrm{VE}$ at the temperature of $600^{\circ} \mathrm{C}$. 
(3) The thermal environment has an obvious influence on the mechanical behaviors of marble specimens under uniaxial compression, especially at $450 \sim 750^{\circ} \mathrm{C}$. This effect of thermal environment on other rocks needs a further investigation.

\section{Conflicts of Interest}

The authors declare that they have no conflicts of interest.

\section{Acknowledgments}

This study was financed by the National Natural Science Foundation of China (nos. 51704279, 51734009, and 51579239) and the Natural Science Foundation of Jiangsu Province of China (no. BK20170270).

\section{References}

[1] F. H. Arna'ot, A. A. Abbass, A. A. Abualtemen, S. R. Abid, and M. Ozakca, "Residual strength of high strength concentric column-SFRC flat plate exposed to high temperatures," Construction and Building Materials, vol. 154, pp. 204-218, 2017.

[2] S. M. Raoof and D. A. Bournas, "Bond between TRM versus FRP composites and concrete at high temperatures," Composites Part B: Engineering, vol. 127, pp. 150-165, 2017.

[3] M. Najafi, S. M. E. Jalali, and R. KhaloKakaie, "Thermalmechanical-numerical analysis of stress distribution in the vicinity of underground coal gasification (UCG) panels," International Journal of Coal Geology, vol. 134, pp. 1-16, 2014.

[4] S. H. Chang, S. W. Choi, and J. Lee, "Determination of the combined heat transfer coefficient to simulate the fireinduced damage of a concrete tunnel lining under a severe fire condition," Tunnelling and Underground Space Technology, vol. 54, pp. 1-12, 2016.

[5] J. He, Q. S. Liu, Z. J. Wu, and X. Y. Xu, "Modelling transient heat conduction of granular materials by numerical manifold method," Engineering Analysis with Boundary Elements, vol. 86, pp. 45-55, 2018.

[6] H. J. Su, H. W. Jing, Q. Yin, L. Y. Yu, Y. C. Wang, and $\mathrm{X}$. J. Wu, "Strength and deformation behaviors of veined marble specimens after vacuum heat treatment under conventional triaxial compression," Acta Mechanica Sinica, vol. 33, no. 5, pp. 886-898, 2017.

[7] Q. Zhang, C. H. Zhang, B. S. Jiang, N. Li, and Y. C. Wang, "Elastoplastic coupling solution of circular openings in strainsoftening rock mass considering pressure-dependent effect," International Journal of Geomechanics, vol. 18, no. 1, p. 04017132, 2018.

[8] B. Mahanta, T. N. Singh, and P. G. Ranjith, "Influence of thermal treatment on mode I fracture toughness of certain Indian rocks," Engineering Geology, vol. 210, pp. 103-114, 2016.

[9] L. Y. Zhang, X. B. Mao, and A. H. Lu, "Experimental study on the mechanical properties of rocks at high temperature," Science in China Series E-Technological Sciences, vol. 52, no. 3 , pp. 641-646, 2009.

[10] T. B. Yin, R. H. Shu, X. B. Li, P. Wang, and X. L. Liu, "Comparison of mechanical properties in high temperature and thermal treatment granite," Transactions of Nonferrous Metals Society of China, vol. 26, no. 7, pp. 1926-1937, 2016.
[11] K. Kim, J. Kemeny, and M. Nickerson, "Effect of rapid thermal cooling on mechanical rock properties," Rock Mechanics and Rock Engineering, vol. 47, no. 6, pp. 2005-2019, 2014.

[12] W. S. Gonzalez-Gomez, P. Quintana, A. May-Pat, F. Aviles, J. May-Crespo, and J. J. Alvarado-Gil, "Thermal effects on the physical properties of limestones from the Yucatan Peninsula," International Journal of Rock Mechanics and Mining Sciences, vol. 75, pp. 182-189, 2015.

[13] M. D. Yao, G. Rong, C. B. Zhou, and J. Peng, "Effects of thermal damage and confining pressure on the mechanical properties of coarse marble," Rock Mechanics and Rock Engineering, vol. 49, no. 6, pp. 2043-2054, 2016.

[14] S. Liu, J. Y. Xu, P. Wang, and X. Y. Fang, "Research on fracture toughness of flattened Brazilian disc specimen after high temperature," High Temperature Materials and Processes, vol. 35, no. 1, pp. 81-87, 2016.

[15] A. P. G. Ferreira, M. C. R. Farage, F. S. Barbosa, A. Noumowe, and N. Renault, "Thermo-hydric analysis of concrete-rock bilayers under fire conditions," Engineering Structures, vol. 59, pp. 765-775, 2014.

[16] J. Wahlqvist and P. van Hees, "Evaluating methods for preventing smoke spread through ventilation systems using fire dynamics simulator," Fire and Materials, vol. 41, no. 6, pp. 625-645, 2017.

[17] Y. Wang, Q. S. Wang, J. X. Wen, J. H. Sun, and K. M. Liew, "Investigation of thermal breakage and heat transfer in single, insulated and laminated glazing under fire conditions," Applied Thermal Engineering, vol. 125, pp. 662-672, 2017.

[18] G. Wu, D. Y. Wang, S. T. Zhai, Y. S. Li, and J. Chen, "Test research on mechanical properties of marble under high temperature," Chinese Journal of Rock Mechanics and Engineering, vol. 31, no. 6, pp. 1237-1244, 2012, in Chinese.

[19] A. Ozguven and Y. Ozcelik, "Effects of high temperature on physico-mechanical properties of Turkish natural building stones," Engineering Geology, vol. 183, pp. 127-136, 2014.

[20] Y. L. Zhang, Q. Sun, H. He, L. W. Cao, W. Q. Zhang, and B. Wang, "Pore characteristics and mechanical properties of sandstone under the influence of temperature," Applied Thermal Engineering, vol. 113, pp. 537-543, 2017.

[21] C. Lu, Q. Sun, W. Q. Zhang, J. S. Geng, Y. M. Qi, and L. L. Lu, "The effect of high temperature on tensile strength of sandstone," Applied Thermal Engineering, vol. 111, pp. 573-579, 2017. 


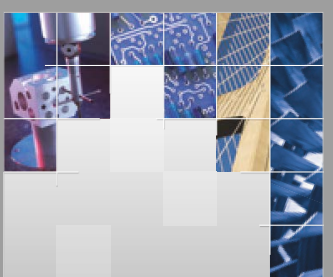

\section{Enfincering}
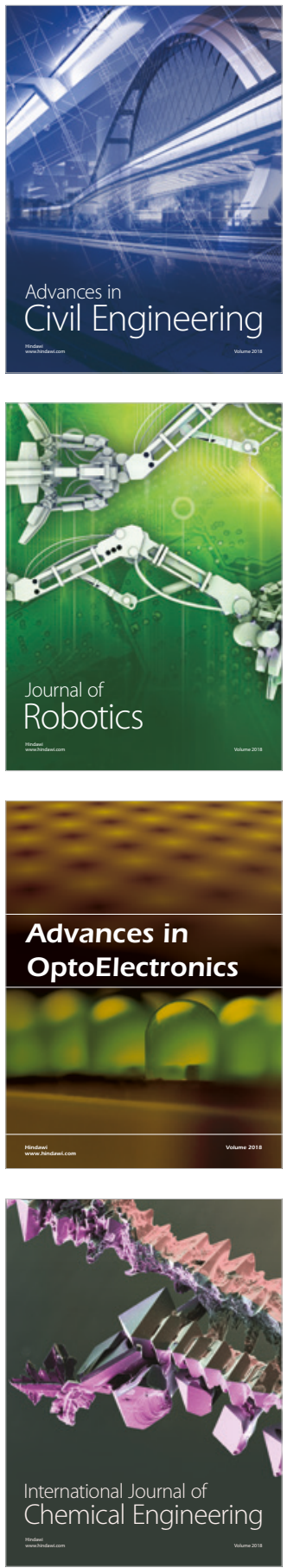

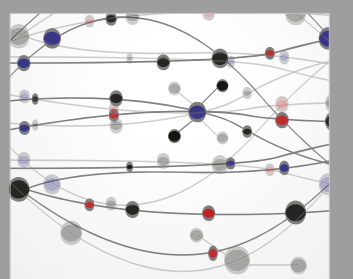

\section{Rotating \\ Machinery}

The Scientific World Journal

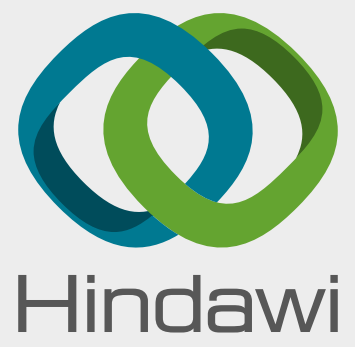

Submit your manuscripts at

www.hindawi.com
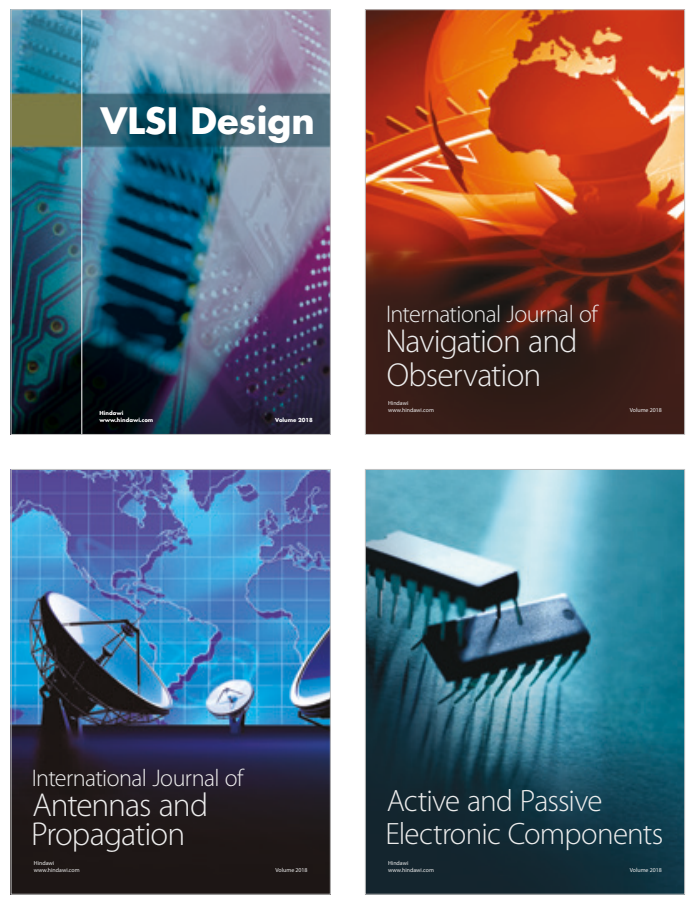
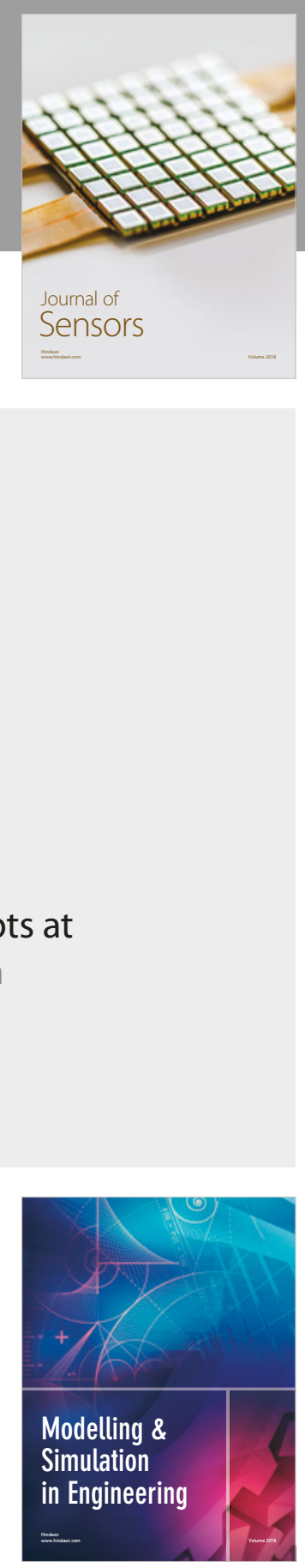

\section{Advances \\ Multimedia}
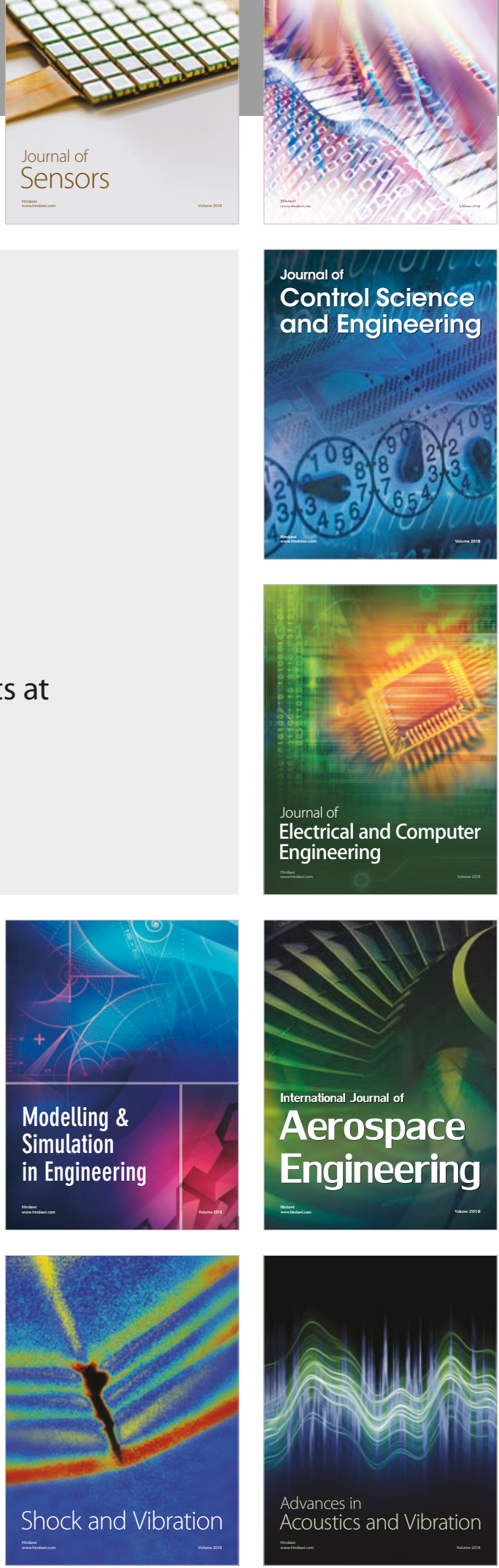